\title{
Preventive Approaches for Post-Stroke Depression: Where Do We Stand? A Systematic Review
}

\author{
Warunya Woranush ${ }^{1,2}$ \\ Mats Leif Moskopp ${ }^{2,3}$ \\ Annahita Sedghi' \\ Isabella Stuckart' \\ Thomas Noll (iD) ${ }^{2}$ \\ Kristian Barlinn' \\ Timo Siepmann'
}

'Department of Neurology, University Hospital Carl Gustav Carus, Technische

Universität Dresden, Dresden, Germany;

${ }^{2}$ Institute of Physiology, Medical Faculty

Carl Gustav Carus, Technische

Universität Dresden, Dresden, Germany;

${ }^{3}$ Vivantes Klinikum im Friedrichshain,

Charité Academic Teaching Hospital,

Klinik für Neurochirurgie, Berlin,

Germany
Correspondence: Timo Siepmann Department of Neurology, University Hospital Carl Gustav Carus, Technische Universität Dresden, Fetschertstr. 74,

Dresden, 01309, Germany

Tel +49 I75-613-14546

Email timo.siepmann@ukdd.de
Purpose: Post-stroke depression (PSD) occurs in one-third of stroke survivors, leading to a substantial decrease in quality of life as well as delayed functional and neurological recovery. Early detection of patients at risk and initiation of tailored preventive measures may reduce the medical and socioeconomic burden associated with PSD. We sought to review the current evidence on pharmacological and non-pharmacological prevention of PSD.

Materials and Methods: We conducted a systematic review using PubMed/MEDLINE and bibliographies of identified papers following Preferred Reporting Items for Systematic Reviews and Meta-Analyses (PRISMA) guidelines, including randomized controlled studies. Eligible studies were included when performed within 1 year after the index cerebrovascular event. Animal and basic research studies, studies lacking a control group, review papers, and case reports were excluded.

Results: Out of 150 studies screened, 37 met our criteria. Among the strategies identified, administration of antidepressants displayed the most robust evidence for preventing PSD, whereas non-pharmacological interventions such as psychotherapy appear to be the most frequently used approaches to prevent depression after stroke. Research suggests that the efficacy of PSD prevention increases with the duration of preventive treatment. Seven out of 11 studies (63\%) that used pharmacological and eight out of $16(50 \%)$ that used nonpharmacological interventions reported a positive preventive effect on PSD.

Conclusion: Overall, the current literature on PSD prevention shows heterogeneity, substantiating a need for well-designed randomized controlled trials to test the safety and efficacy of pharmacological as well as non-pharmacological and composite prevention regimens to minimize the risk of PSD in stroke survivors. Integrative strategies combining personalized non-pharmacological interventions such as educational, mental, and physical health support, and pharmacological strategies such as SSRIs may be the most promising approach to prevent PSD.

Keywords: PSD, antidepressant, depression, prevention, stroke

\section{Introduction}

Stroke is a major health problem, affecting 16 million people each year, and is one of the global leading causes of death and disability in adults. ${ }^{1}$ Around $30 \%$ of stroke survivors develop affective symptoms after stroke that cannot be explained by emotional response to illness alone and have been classified as post-stroke depression (PSD). ${ }^{2-4}$ The diagnosis is indexed by the Diagnostic and Statistical Manual of Mental Disorders, Fifth Edition (DSM-5), which defines PSD as 
a "depressive disorder due to stroke". ${ }^{5}$ Diagnostic DSM-5 relies on five diagnostic criteria, including a prominent and persistent period of depressed mood or markedly diminished interest or pleasure for at least 2 weeks, while important differential diagnoses include pre-existing depressive disorder, adjustment disorder, or medicationinduced disorder. ${ }^{5,6}$ The natural course of untreated PSD is described to last for 7-8 months, with a peak of symptoms at 6 months to 2 years post-stroke. ${ }^{7,8}$ A diagnosis of PSD has been shown to be associated with a decrease in quality of life and life expectancy, as well as psychosocial effects comprising deleterious relationships between affected patients and healthcare givers or relatives. ${ }^{9-11}$ Moreover, the development of PSD is linked to an increment in socioeconomic burden, with an increase in strokerelated mean lifetime costs in the range of $\$ 47,790-77,864$ in the USA. ${ }^{12}$ A recent meta-analysis as well as a recently published review found the following significant risk factors for PSD: stroke characteristics, including stroke severity, as well as physical and cognitive impairment associated with functional dependency, female gender, age, medical history of mental disorders, and neuroticism. ${ }^{13,14}$ Furthermore, social support is a preventive factor for PSD. ${ }^{13}$ There is an ongoing scientific debate on the degree to which PSD results from ischemic brain organic changes and how the location of the stroke lesion contributes to the development of depressive symptoms. ${ }^{15-17}$ On the other hand, the extent to which PSD can be explained by psychodynamic and environmental factors, such as self-powerlessness, has also been discussed. ${ }^{18,19}$ A comparison of patients with stroke and patients with matched orthopedic injuries revealed a significantly smaller risk for depression in the group of orthopedic patients, indicating PSD as a stroke-specific complication. $^{20}$

The majority of previous studies focused on pharmacotherapeutics and behavioral treatment of PSD to alleviate depressive symptoms and improve recovery from stroke through the utilization of selective serotonin reuptake inhibitors (SSRIs), exercise, and music therapy. Although these treatment strategies have displayed efficacy and safety and have been successfully translated into clinical practice, the most effective strategy to prevent PSD in stroke survivors is unknown. ${ }^{21,22}$ In addition, most previous literature reviews have addressed strategies of PSD treatments that comprised either pharmacological or psychological interventions. ${ }^{23,24}$ Therefore, we aimed to systematically review the current literature on pharmacological and non-pharmacological strategies to prevent PSD in patients with acute stroke. The greater goals of this systematic review are to characterize the present research gap in PSD prevention and to form a basis for designing interventional studies to close this gap.

\section{Materials and Methods}

The present review employed a systematic literature search according to the Preferred Reporting Items for Systematic Reviews and Meta-Analyses (PRISMA) guidelines. ${ }^{25}$ This review was not pre-registered.

\section{Literature Search}

A literature search was performed using the PubMed/ MEDLINE database. The search strategy included the following combinations of search terms with all associated Medical Subject Headings (MeSH) and boolean operators: ("prevention" OR "preventive") AND ("depression" OR "depressive") AND ("post-stroke" OR "stroke" OR "cerebrovascular event" OR "cerebrovascular accident"). Selected filters comprised "clinical trial", "meta-analysis", "randomized controlled trial", "humans", and "English". The date of the last search was set from inception to 31st March 2021. The complete search string including MeSH terms is provided in the online supplement. We explicitly chose to search MEDLINE via the interface for our main search to identify the most important and relevant studies. However, in order to access the included meta-analyses and extract gray literature, we also used Embase, Scopus, CENTRAL, Clinicaltrials.gov, Wanfang Data, VIP, CNKI, PsycINFO, CINHAL, and Cochrane Library databases.

\section{Study Selection Criteria}

We included interventional randomized controlled trials (RCTs) and meta-analyses reporting on any pharmacological or non-pharmacological strategy to prevent PSD. On a preliminary search, we found that institutional protocols on diagnosing PSD differ substantially among hospitals. This heterogeneity is also reflected by a substantial variety of screening and assessment tools for PSD, such as the Geriatric Depression Scale (GDS), Hospital Anxiety and Depression Scale (HADS), Patient Health Questionnaire (PHQ-9), Beck Depression Inventory (BDI I-III), Center for Epidemiological Studies Depression Scale (CES-D) and Depression, Obstructive sleep apnea and Cognitive impairment screen (DOC). This variability in assessment has been 
addressed by the Canadian stroke best practice recommendations. ${ }^{26}$ Even though PSD can occur in a range of 1 month to 5 years after a stroke, ${ }^{4}$ our review focuses on prevention and therefore we limited the time until recruitment after stroke for eligible studies to 1 year after the index cerebrovascular event. We included only papers written in the English language. We excluded animal and basic research studies, studies lacking a control group, review papers, and case reports. Within this systematic review, any studies that recruited stroke patients with non-depression or mild depression, or early treatment with any intervention, were included as prevention approaches for PSD. The objective of this study is further detailed in PICO format, as shown in Table 1.

\section{Assessment of Articles and Study Quality}

Two independent reviewers (WW and MM) screened all articles identified by an assessment of titles and abstracts for eligibility, and the subsequent retrieval and assessment of full texts where abstracts did not provide sufficient information for the evaluation of methodology and results. Reviewers resolved any disagreements by consensus. Then, all papers that met our criteria were evaluated by two independent reviewers (WW and MM), with insertion of extracted data into a standardized data extraction form (Excel; Microsoft, Redmond, WA, USA).

The retrieved data included author names, year and country of publication, trial quality, number of patients, recruitment period after stroke, study duration, study approach, and outcomes. Outcomes were extracted and listed as reported by each study. Study quality was assessed using the Oxford quality scoring system (Jadad scale).

Table I Research Questions and Study Approaches (PICO Format)

\begin{tabular}{|l|l|}
\hline \multicolumn{2}{|l|}{ PICO } \\
\hline $\begin{array}{l}\text { P (Patient/ } \\
\text { Population) }\end{array}$ & $\begin{array}{l}\text { Early treatment, non-depressed or mildly } \\
\text { depressed patients recruited from immediately } \\
\text { until up to I year after cerebrovascular event } \\
\text { (stroke) }\end{array}$ \\
\hline I (Intervention) & $\begin{array}{l}\text { Pharmacological and non-pharmacological } \\
\text { interventions for PSD prevention }\end{array}$ \\
\hline C (Comparison) & Compared to control or placebo within groups \\
\hline O (Outcomes) & New depression occurrence or depression scale \\
\hline
\end{tabular}

\section{Clustering of Included Studies per Study Design}

The selected studies were divided into four categories based on the type of preventive strategies applied in each study. They were categorized into 1) randomized controlled studies testing antidepressant drugs for PSD prevention, 2) randomized controlled studies assessing nonpharmacological strategies for PSD prevention, 3) randomized controlled studies combining pharmacological and non-pharmacological strategies, and 4) meta-analyses on PSD prevention strategies.

\section{Clustering of Included Studies per Preventive Intervention Type}

We classified preventive strategies for PSD into three main categories, comprising 1) pharmacological antidepressants, 2) physical and psychosomatic therapy such as mobility programs, exercise, and mind-body programs, and 3) psychological therapy, including social support and social connections between medical staff, friends, and family of the PSD patients. Psychological therapy could also be conducted by telephone interview, home visit, follow-up, clinical empathy and enabling coping strategies, as well as pathological education on PSD.

\section{Results}

\section{Characteristics of Included Studies}

From the search strategy, 150 studies were retrieved. Out of these, 99 were excluded based on screening of titles and abstracts. Of the remaining 51 studies, 14 studies were excluded following full-text screening based on the evaluation of the study design, quality of the data report, or study population, and 37 eligible studies were included, as depicted in Figure 1.

\section{Antidepressant Drugs for Prevention of Post-Stroke Depression}

We identified 11 randomized controlled studies comprising 7089 patients testing the use of antidepressants for PSD prevention. ${ }^{27-37}$ Diagnostic tools such as DSM-IV or DSM-5, as well as screening tools such as the Hamilton Depression Scale (HAM-D) and Montgomery-Asberg Depression Rating Scale (MADRS), were frequently used for the assessment of outcomes. All included studies recruited patients between less than 24 hours and a maximum duration of 1 month after stroke onset. 


\section{No. of records identified through database searching $n=150$}

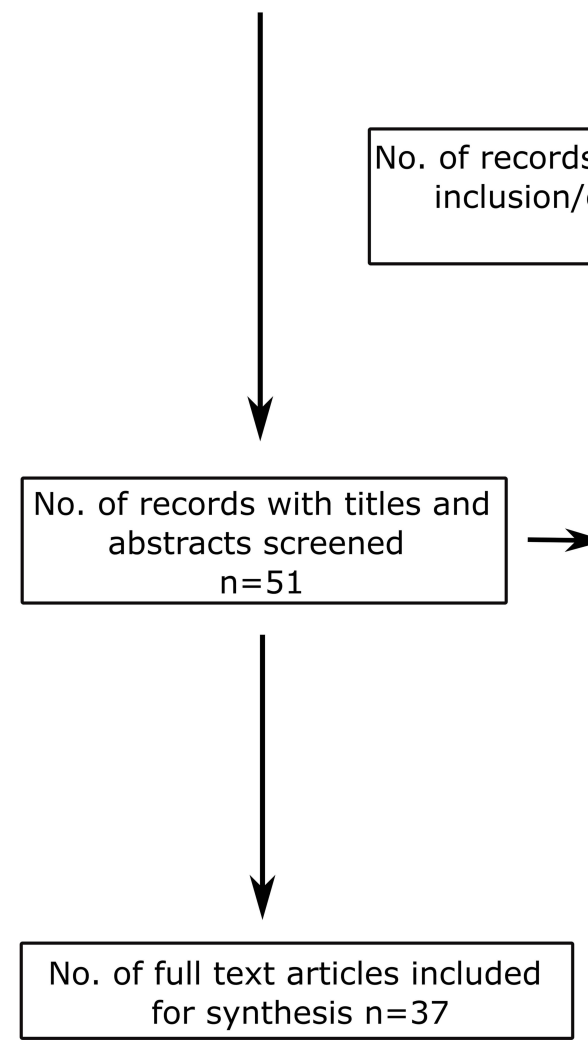

Figure I Preferred Reporting Items for Systematic Reviews and Meta-Analyses (PRISMA) flowchart.

Notes: The flow diagram depicts the flow of information through the different phases of this scoping review. Adapted from: Moher D, Liberati A, Tetzlaff J, Altman DG, Altman D; PRISMA group. Preferred reporting items for systematic reviews and meta-analyses: The PRISMA statement. Ann Intern Med. 2009;15I(4):264-249. Creative Commons. ${ }^{25}$

Abbreviations: PSD, post-stroke depression; No., number.

Antidepressants tested comprised the noradrenergic and specific serotonergic antidepressants (NaSSAs) mirtazapine and milnacipran, the selective serotonin reuptake inhibitors (SSRIs) sertraline, fluoxetine, and escitalopram, the serotonin and norepinephrine reuptake inhibitor (SNRI) duloxetine, and the tetracyclic antidepressant mianserin. Study durations ranged from 3 to 12 months. Seven out of 11 studies reported the efficacy of antidepressive medication, including mirtazapine $\left(\mathrm{n}=70,{ }^{27} \mathrm{PSD}\right.$ in $5.7 \%$ mirtazapine vs $40 \%$ non-treated, $P=0.001$ ), milnacipran $\left(\mathrm{n}=92,{ }^{28} \mathrm{PSD}\right.$ in $2.2 \%$ milnacipran vs $15.2 \%$ placebo, $P=0.048$ ), sertraline ( $\mathrm{n}=137,{ }^{31}$ PSD in $10 \%$ sertraline vs $30 \%$ placebo, $P \leq 0.05)$, fluoxetine $\left(n=3127,{ }^{34}\right.$ PSD in $13.4 \%$ fluoxetine vs $17.2 \%$ placebo, $P=0.0033$; and $\mathrm{n}=1500,{ }^{37} \mathrm{PSD}$ in $7 \%$ fluoxetine vs $11 \%$ placebo, $P=0.015$ ), duloxetine ( $\mathrm{n}=97,{ }^{35}$ PSD in $8.3 \%$ duloxetine vs $24.5 \%$ control, $P<0.05)$, and escitalopram $\left(\mathrm{n}=97,{ }^{36}\right.$
PSD in $10.2 \%$ escitalopram vs $50.3 \%$ control, $P<0.01)$ in preventing PSD. The results of four trials indicated that sertraline $(n=111),{ }^{30}$ escitalopram $(n=478),{ }^{32}$ fluoxetine $(\mathrm{n}=1280),{ }^{29}$ and mianserin $(\mathrm{n}=100)^{33}$ do not prevent PSD in stroke survivors. Regarding the study on mianserin, it was concluded that the prevalence of depression was low in both mianserin-treated groups as well as in the placebo group, potentially masking the real effect of mianserin on PSD prevention. ${ }^{33}$ Two clinical trials tested the efficacy of sertraline in preventing PSD. ${ }^{30,31}$ When sertraline was administered in a long-term titration regimen, eg with a starting dose of $50 \mathrm{mg}$ per day and consecutive stepwise increase to $150 \mathrm{mg}$ per day within 12 months of treatment, a preventive effect of PSD could be observed. ${ }^{31}$ By contrast, short-term low-dose treatment with sertraline $50 \mathrm{mg}$ per day for 6 months showed no efficacy in preventing PSD. $^{30}$ 
With regard to the study duration, three out of four studies (75\%) reported effective PSD prevention using long-term regimens of 12 months of antidepressants (mirtazapine, milnacipran, and sertraline). ${ }^{27,28,31,33}$ Two out of three studies (67\%) observed PSD prevention following 6 months of pharmacotherapy with fluoxetine..$^{29,34,37}$ Two out of three studies $(67 \%)$ described a preventive effect of PSD after a 3-month treatment regimen with duloxetine or escitalopram..$^{32,35,36}$ Fluoxetine has been investigated for its effects on functional outcome as the primary outcome and depression as the secondary outcome in stroke patients by three large multicenter RCTs. Patients who were enrolled in these studies had the common characteristic of having had acute stroke in the previous 2-15 days, brain imaging consistent with ischemic or hemorrhagic stroke, and a persisting neurological deficit. Patients were randomized and were taking $20 \mathrm{mg}$ fluoxetine or matching placebo daily for 6 months. Follow-up was planned to assess the patients at 6 and 12 months. All three studies reported that daily $20 \mathrm{mg}$ fluoxetine for 6 months had no effect on the functional outcome of stroke patients.

The FOCUS (Fluoxetine Or Control Under Supervision) trial enrolled 3127 patients in 103 UK hospitals. The results of this study showed that $20 \mathrm{mg}$ fluoxetine administered over 6 months led to a decrease in the frequency of newly diagnosed depression post-stroke compared to placebo at 6 months $(13.43 \%$ vs $17.21 \%$; difference $3.78 \%, \quad 95 \%$ CI $1.26-6.30 ; \quad P=0.0033)$. However, this antidepressive effect of fluoxetine was no longer significant at the 12-month follow-up and did not translate into improvement of functional outcome after stroke. $^{34}$ The EFFECTS (Efficacy oF Fluoxetine a randomizEd Controlled Trial in Stroke) study enrolled 1500 patients at 35 centers in Sweden. The results of this large RCT showed that $20 \mathrm{mg}$ fluoxetine decreases the proportion of patients with newly diagnosed depression after 6 months compared to placebo (7\% vs $11 \%$; $95 \%$ CI 0.71-6.49; $P=0.015)$. However, like the FOCUS trial, it failed to demonstrate any effect on functional outcome after stroke. $^{37}$ The AFFINITY (Assessment oF FluoxetINe In sTroke recoverY) study, from Australia, New Zealand, and Vietnam, found no preventive effect of fluoxetine on the occurrence of PSD after 6 months compared with placebo in 1280 patients $(5 \%$ vs $7 \%$; $P=0.13$ ). The authors explained this observation as being a consequence of an overall low absolute frequency of depression. ${ }^{29}$ Details of the included studies on antidepressant drugs for the prevention of PSD are given in Table 2.

\section{Non-Pharmacological Interventions to Prevent Post-Stroke Depression}

We identified 16 studies conducted in 10 countries (testing seven non-pharmacological interventions) to prevent PSD in a total of 2875 stroke survivors. ${ }^{38-53}$ The duration of intervention varied from 2 weeks to 18 months. DSM-IV, HAM-D, MADRS, HADS, and BDI were frequently used in these studies as diagnostic or screening tools, as well as to determine depressive outcomes after testing. Investigational preventive strategies can be categorized into:

1. Exercise programs (total number of study participants: $\mathrm{n}=509$; individual samples: $\mathrm{n}=100,{ }^{39}$ $\left.\mathrm{n}=362,{ }^{52} \mathrm{n}=55\right)^{41}$

2. Intensive integrated mental care and education programs (total number of study participants: $n=662$; individual samples: $\mathrm{n}=196,{ }^{38} \mathrm{n}=233,{ }^{49} \mathrm{n}=38,{ }^{50}$ $\mathrm{n}=195)^{42}$

3. Nurse-led programs $(n=459)^{46}$

4. Distant mental support programs (total number of study participants: $\mathrm{n}=975$; individual samples: $\left.\mathrm{n}=536,{ }^{47} \mathrm{n}=186,{ }^{48} \mathrm{n}=52,{ }^{51} \mathrm{n}=201\right)^{40}$

5. Rehabilitation training with additional support (total number of study participants: $\mathrm{n}=192$; individual samples: $\left.n=168,{ }^{53} n=24\right)^{44}$

6. Life review therapy $(n=14)^{45}$

7. Meridian acupressure $(n=56)^{43}$

The most frequently assessed non-pharmacological PSD prevention strategies were "intensive, integrated mental care and education intervention" and "distant mental support program". Both were employed in four RCTs, while "exercise programs" were tested in three RCTs.

The evidence supporting the different forms of nonpharmacological interventions to prevent PSD was heterogeneous. Exercise programs comprising resistance training or balance exercise for the prevention of PSD were tested in three randomized controlled studies. ${ }^{39,41,52}$ Intensive integrated mental care and education strategies were assessed in several studies. ${ }^{38,42,49,50}$ A randomized controlled study showed reductions in cognitive impairment, anxiety, and depression in patients with acute ischemic stroke who underwent an intensive caregiver education program. ${ }^{38}$ In another randomized controlled study, an integrated care model providing ongoing collaboration between a specialist stroke service and the primary care 


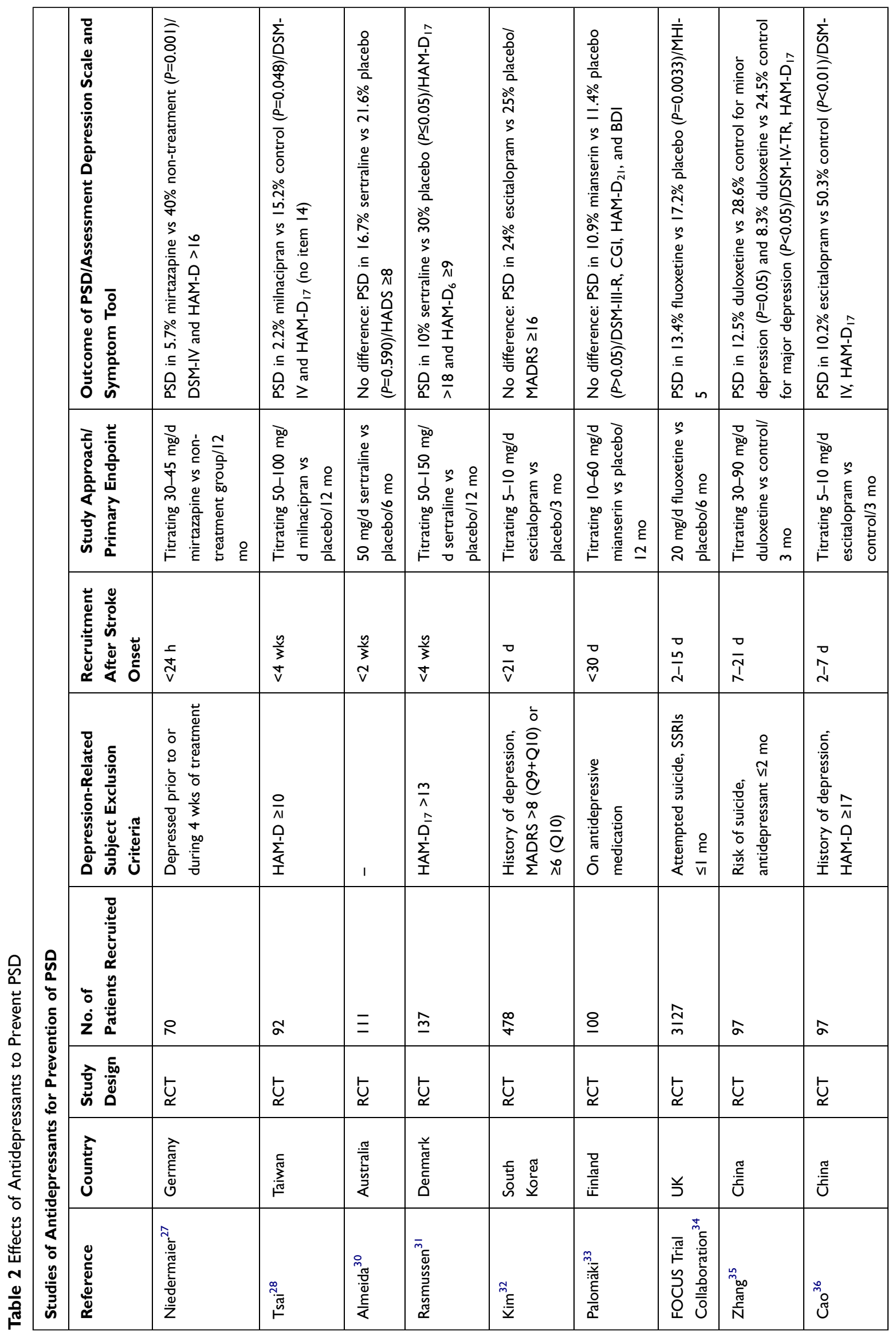




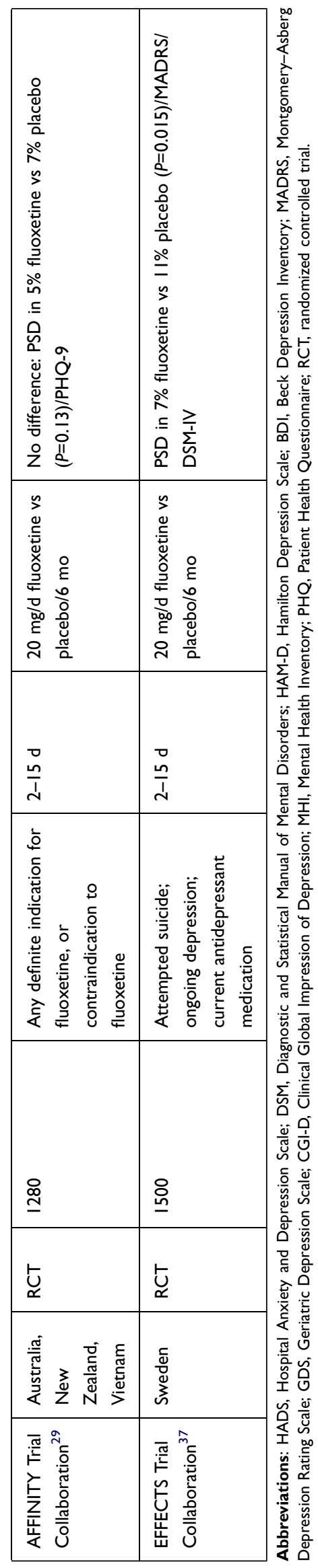

physician led to a lower rate of PSD in stroke survivors than in patients in the standard care arm. ${ }^{49}$ A monocentric randomized controlled study of self-management training showed an improvement in modifiable cardiovascular risk factors such as blood pressure and $\mathrm{HbA}_{1 \mathrm{c}}$, but no clear effect on PSD rates. ${ }^{50} \mathrm{~A}$ randomized, evaluator-blinded, controlled trial demonstrated a lower prevalence of depressive symptoms 1 year after stroke in patients who underwent a structured program with multidisciplinary rehabilitation. ${ }^{42}$ Two RCTs tested rehabilitation training with additional support interventions in stroke survivors, and of these, one study reported a post-interventional reduction in PSD incidence, ${ }^{53}$ whereas the other study showed no such effect. ${ }^{44}$ Consistent with the latter study, four trials of distant mental support, including motivational interview, ${ }^{51}$ education/support via telephone, ${ }^{47,48}$ and postcards, ${ }^{40}$ observed no effect of the tested nonpharmacological interventions on PSD prevention. By contrast, preventive effects on PSD were observed by trials in stroke survivors undergoing life review therapy, ${ }^{45}$ a nurse-led program, ${ }^{46}$ and meridian acupressure. ${ }^{43}$

Based on the most common approaches of non-pharmacological intervention achievements, including 11 out of 16 studies, it can be summarized that one out of three exercise program trials $(33 \%)$ reported a successful intervention to prevent PSD. ${ }^{39,41,52}$ Three out of four studies (75\%) demonstrated lower depression symptoms in stroke patients who received 12 months of intensive integrated mental care and education compared to the control groups. ${ }^{38,49,50}$ In contrast, zero out of four studies $(0 \%)$ using distant mental support showed any preventive effect on PSD. ${ }^{40,47,48,51}$ Details on the included studies on non-pharmacological interventions to prevent PSD are listed in Table 3.

\section{Multiple Intervention Comparison Studies}

We identified five trials that evaluated at least two types of intervention for the prevention of PSD. ${ }^{54-58}$ Among these studies, a smaller three-arm RCT $(n=48)$ compared the effects of fluoxetine, nortriptyline, and placebo on PSD prevention. ${ }^{58}$ In this study, dosages of fluoxetine were titrated from an initial dose of $25 \mathrm{mg}$ per day to a daily dosage of $100 \mathrm{mg}$, whereas daily dosages of nortriptyline were titrated from an initial dose of $10 \mathrm{mg}$ to $40 \mathrm{mg}$ over a period of 3 months. This study showed a higher response rate and a reduced risk of PSD in patients treated with nortriptyline compared to fluoxetine and placebo. In the nortriptyline-treated group, stroke survivors developed minor depression at $7.7 \%$, whereas in the fluoxetine-treated 


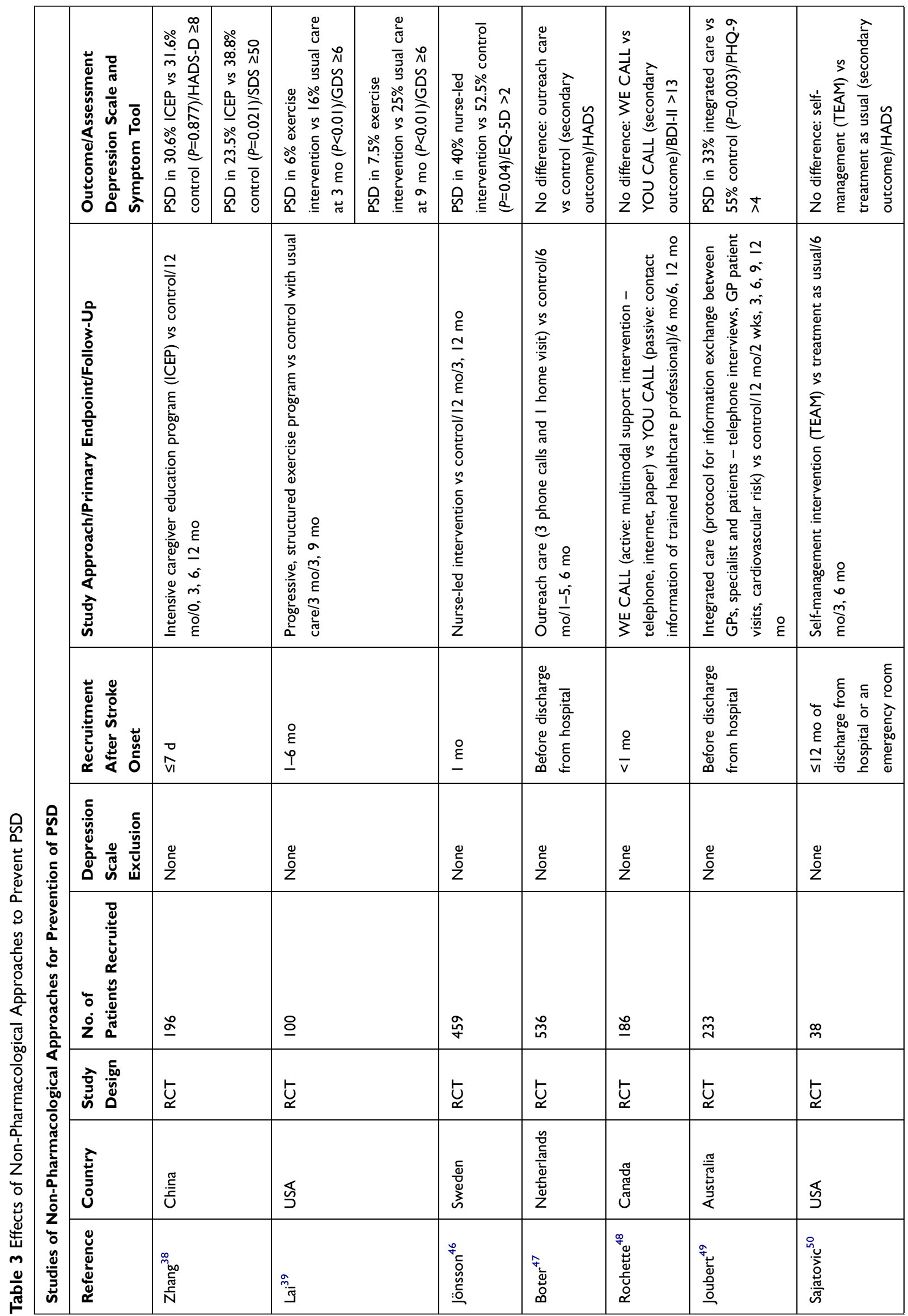




\begin{tabular}{|c|c|c|c|c|c|c|c|c|}
\hline 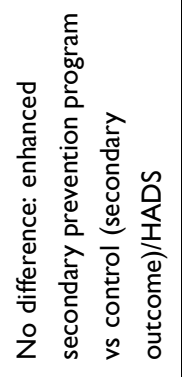 & 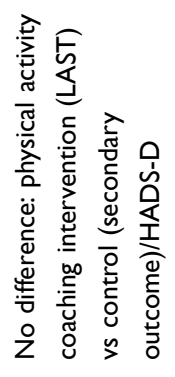 & 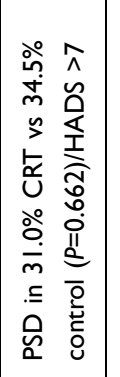 & 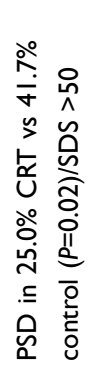 & 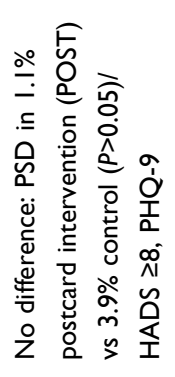 & 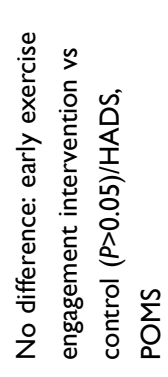 & 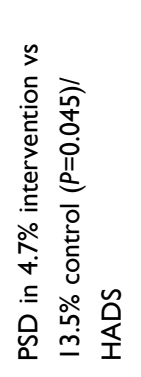 & 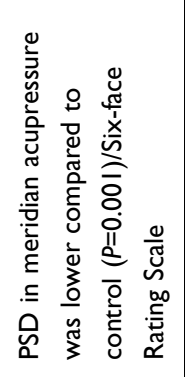 & 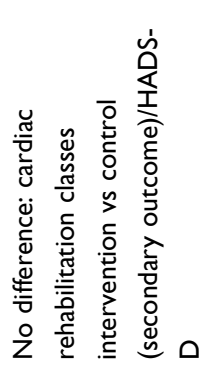 \\
\hline 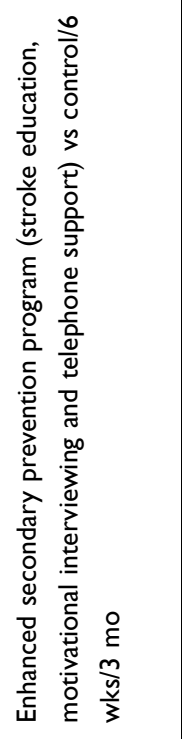 & 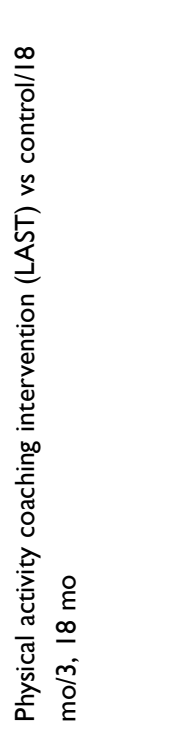 & 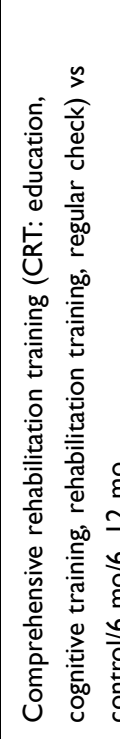 & & 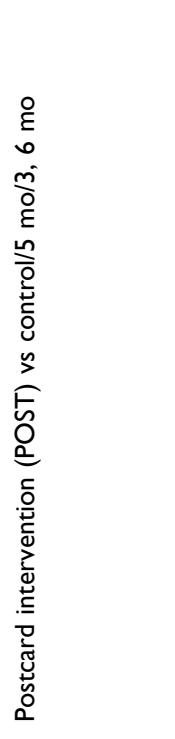 & 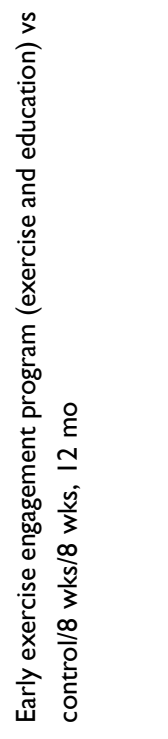 & 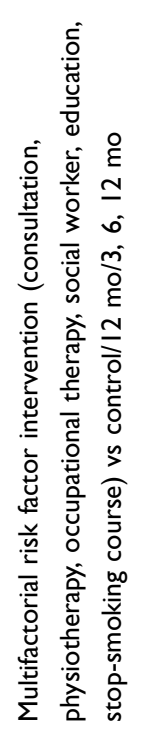 & 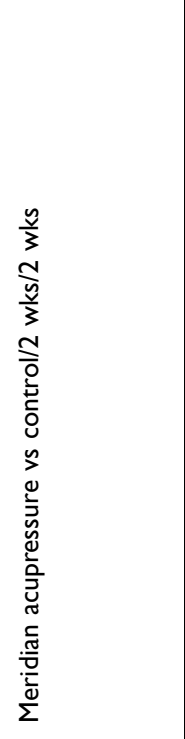 & 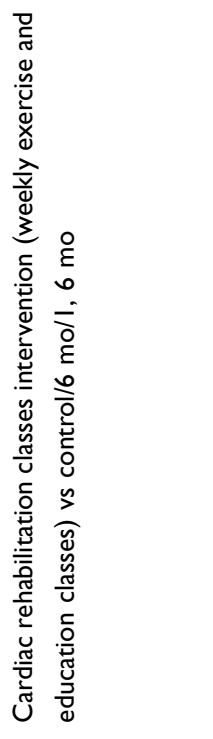 \\
\hline 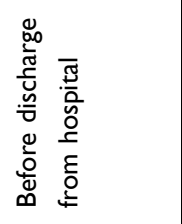 & $\stackrel{\stackrel{\circ}{\xi}}{m}$ & 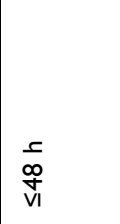 & & $\begin{array}{l}\frac{y}{3} \\
\infty \\
\mathscr{v}\end{array}$ & $\begin{array}{l}\hat{v} \\
\hat{v}\end{array}$ & 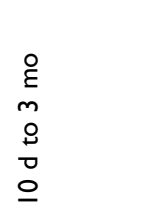 & $\begin{array}{l}\frac{y}{3} \\
\tilde{\Lambda}\end{array}$ & 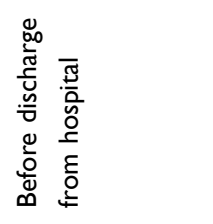 \\
\hline $\begin{array}{l}0 \\
\stackrel{0}{0} \\
\text { Z }\end{array}$ & $\begin{array}{l}0 \\
\stackrel{0}{0} \\
\text { z }\end{array}$ & 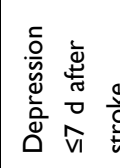 & & 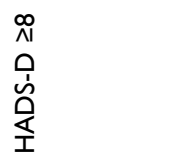 & $\begin{array}{l}0 \\
\stackrel{0}{0} \\
z\end{array}$ & $\begin{array}{l}0 \\
\stackrel{0}{0} \\
z\end{array}$ & $\begin{array}{l}0 \\
\stackrel{0}{0} \\
z\end{array}$ & $\begin{array}{l}0 \\
\stackrel{0}{0} \\
z\end{array}$ \\
\hline กี & స్లి & $\stackrel{\infty}{\underline{\infty}}$ & & $\bar{i}$ & 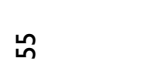 & $\underline{\underline{\alpha}}$ & น゚ & $\stackrel{ \pm}{\sim}$ \\
\hline ঢ্ & $\underset{\swarrow}{\longleftarrow}$ & $\underset{\propto}{\mathfrak{u}}$ & & $\underset{\check{\complement}}{\llcorner}$ & $\underset{\propto}{\longleftarrow}$ & $\underset{\propto}{\mathfrak{t}}$ & $\underset{\propto}{\check{E}}$ & $\underset{\propto}{\mathfrak{\Xi}}$ \\
\hline 弚 & $\begin{array}{l}\text { त्र } \\
\frac{3}{0} \\
\text { z }\end{array}$ & 默 & & 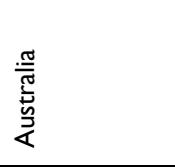 & 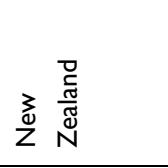 & $\begin{array}{l}\text { ते } \\
\stackrel{3}{0}\end{array}$ & 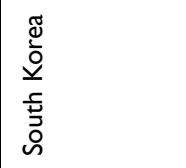 & 弚 \\
\hline 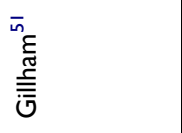 & 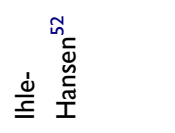 & 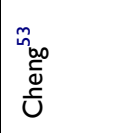 & & 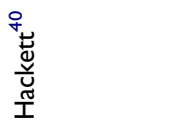 & 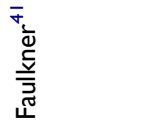 & 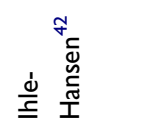 & 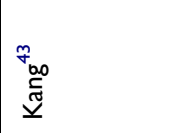 & 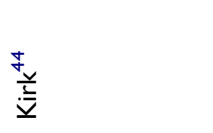 \\
\hline
\end{tabular}




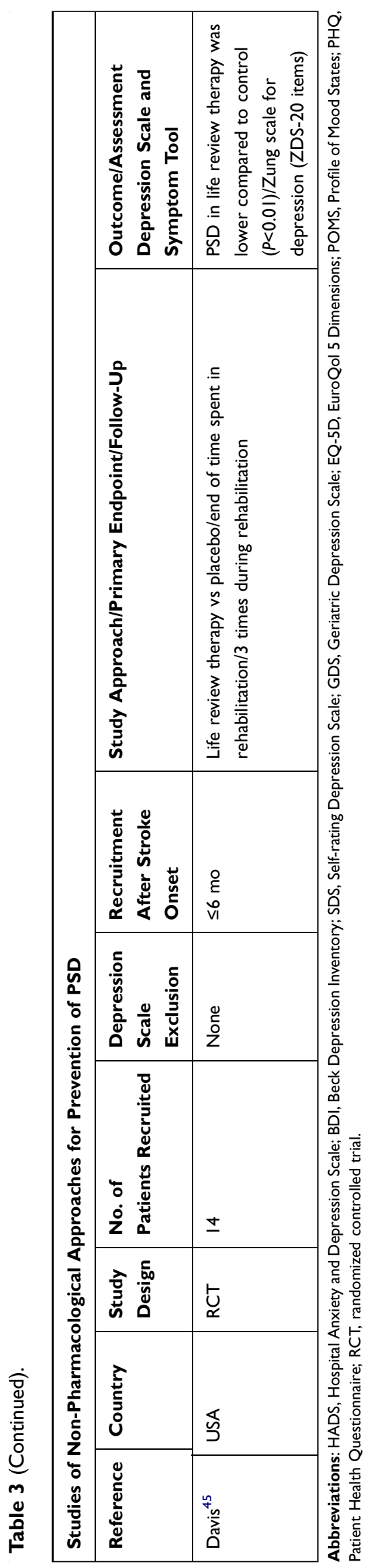

group and in the placebo group, PSD rates of $20.0 \%$ and $33.3 \%$, respectively, were observed after 3 months. When symptoms of depression were quantified using the Hospital Depression Score (HDS), nortriptyline and fluoxetine showed higher efficacy compared to placebo patients immediately and 3 months after discontinuation of treatment. In addition, 6 months after discontinuation, nortriptyline-treated patients had an almost two-fold higher HDS than those who received fluoxetine or placebo. Another RCT and its follow-up compared escitalopram with behavioral problemsolving therapy (PST) in addition to standard care. ${ }^{54,56}$ In these two studies, patients were recruited within 3 months after stroke onset and received escitalopram for 12 months, 12 sessions of PST, or placebo medication. Observations deriving from these trials were inconsistent. The initial multicentric, randomized placebo-controlled study with 176 participants showed that both the escitalopram-treated group and the PST group were less likely to develop depression compared to the placebo group (PSD in $8.5 \%, 11.9 \%$, and $22.4 \%$, respectively). ${ }^{54}$ However, after applying an intention-to-treat approach and adjusting for a past history of mood disorder $(\mathrm{n}=27)$, escitalopram showed higher efficacy in preventing PSD compared with placebo and PST (PSD in $23.1 \%, 34.5 \%$, and $30.5 \%$, respectively). By contrast, another placebo-controlled study $(\mathrm{n}=108)$ could not demonstrate any effect of escitalopram or PST on PSD prevention. ${ }^{56}$ Furthermore, we identified two RCTs assessing non-pharmacological multimodal interventions for PSD prevention. Both studies tested interventions delivered by trained and specialized health professionals to improve coping skills, PST, and self-management. ${ }^{55,57}$ The results of one of these trials $(n=33)$ suggested that measures to improve coping skills and self-management do not have any sustained protective effect on PSD. ${ }^{55}$ The other study observed lower depression scores on the General Health Questionnaire (GHQ-28) in stroke survivors who underwent PST interventions compared to a volunteer support group and standard care. However, these results no longer reached statistical significance after GHQ scores were converted into caseness scores to classify depression. ${ }^{57}$

Details of the included studies on multimodal strategies to prevent PSD are listed in Table 4.

\section{Study Quality}

Seven out of 11 RCTs (73\%) reporting on antidepressants for PSD prevention displayed good study quality. Ten out of 16 RCTs (63\%) reporting on non-pharmacological approaches for PSD prevention displayed good study 


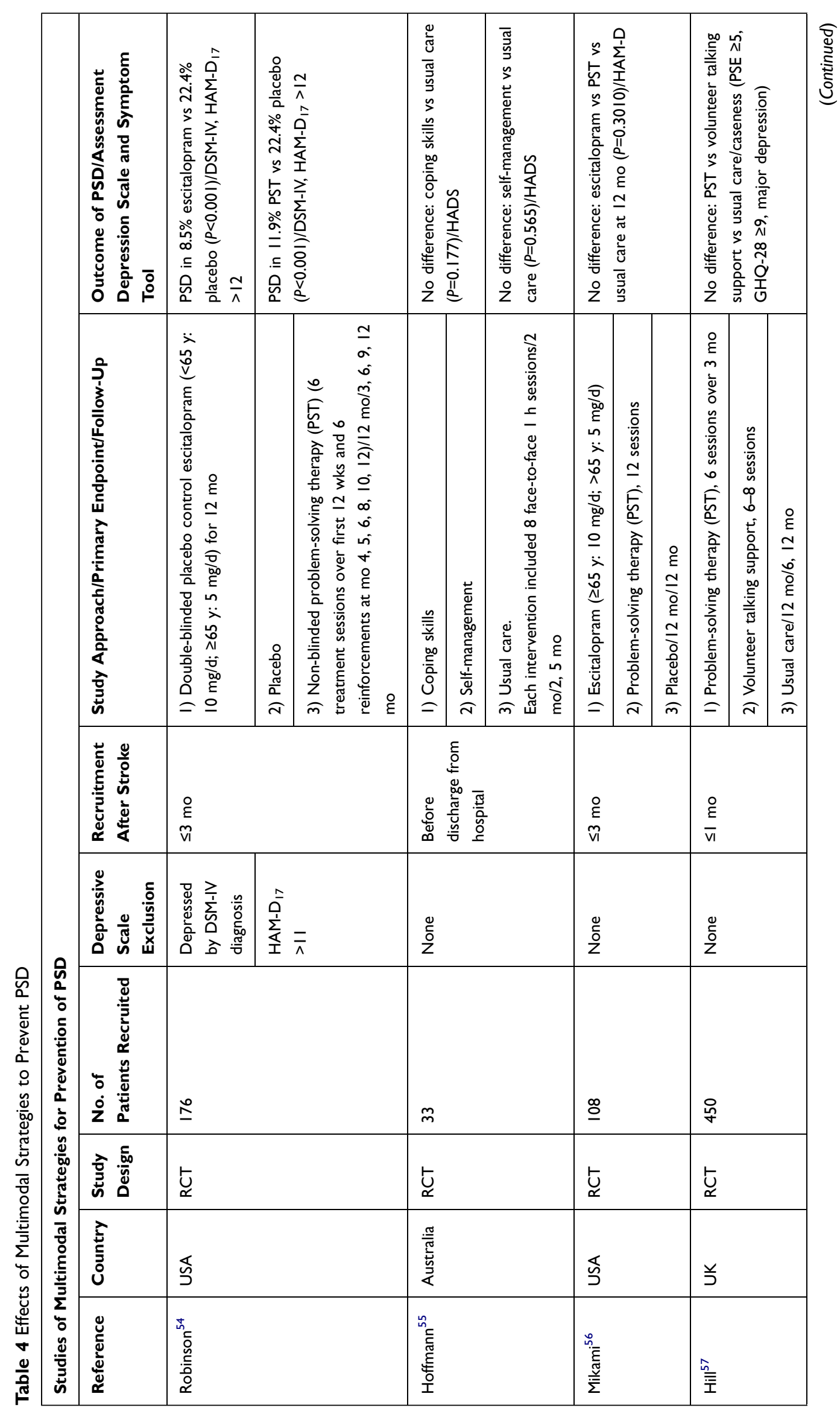




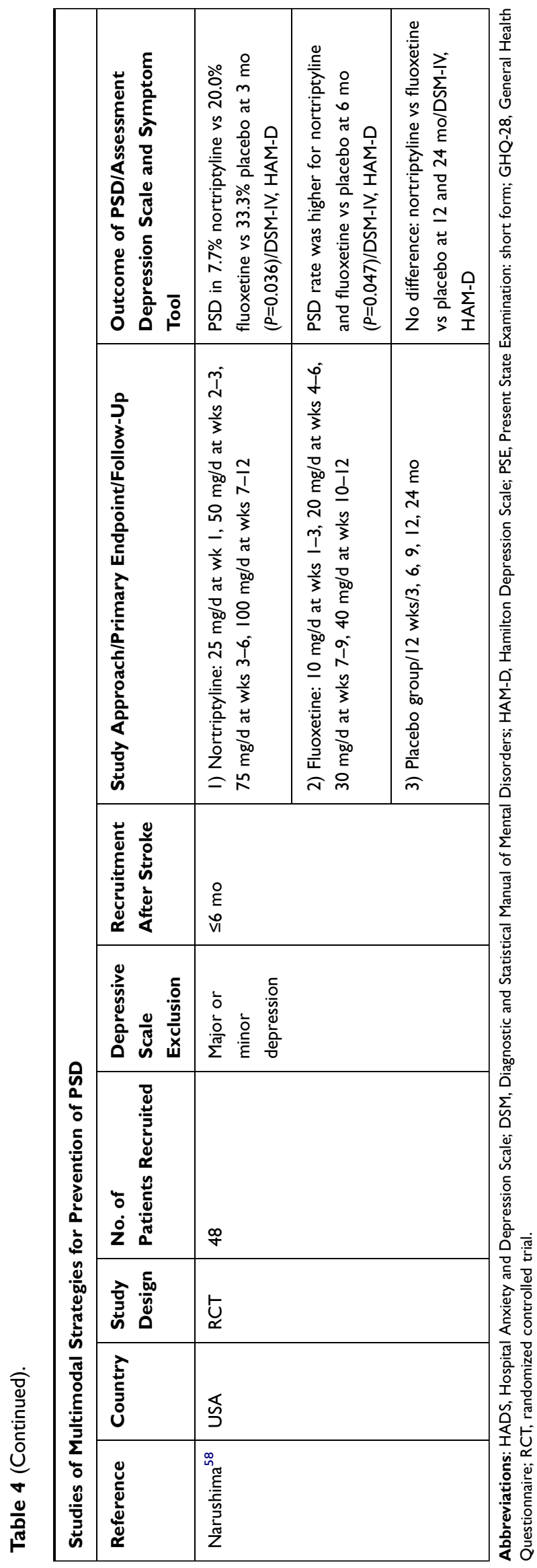

quality. Four out of five RCTs $(80 \%)$ reporting on multimodal approaches for PSD prevention displayed good study quality. Details are listed in Table 5.

\section{Meta-Analytic Evidence on the Prevention of PSD Using Antidepressants}

Five meta-analyses on the prevention of depression in stroke survivors were identified. ${ }^{59-63}$ The databases used in these analyses were PubMed/MEDLINE, Embase, Cochrane Library, Cochrane Central Register of Controlled Trials (CENTRAL), PsycINFO, and CINAHL. The Chinese databases Wanfang Data, Chinese Scientific Journals database (VIP), and China National Knowledge Infrastructure (CNKI) were additionally searched in two of the included metaanalyses. ${ }^{59,60}$ Depression rating scores and PSD incidence after treatment were assessed as either primary or secondary outcomes. Morbidity, functional independency, activities of daily living, and adverse events regarding post-stroke were also evaluated in these studies. The time interval of the literature search in the five identified meta-analyses ranged from 1st January 2018 to 31st March 2021.

A total of 35 RCTs were included in the five meta-analyses. Out of these, the studies by Rasmussen et $\mathrm{al}^{31}$ and Almeida et $\mathrm{al}^{30}$ were the only trials that were included in all five metaanalysis studies, followed by the randomized placebo-controlled fluoxetine for motor recovery after acute ischaemic stroke (FLAME) trial, published by Chollet et al, ${ }^{64}$ which was included in three of the included five meta-analyses. In the FLAME study, patients with ischemic stroke and moderate to severe motor deficit displayed enhanced motor recovery after 3 months following the early prescription of fluoxetine with physiotherapy, even after adjustment for depression. It is noteworthy that the objective of this study was not to prevent PSD but to facilitate recovery from stroke. A similar study, The Efficacy of Citalopram Treatment in Acute Stroke (TALOS), also showed beneficial effects on stroke recovery and was included in previous data syntheses. ${ }^{65}$ Seven studies appeared in two of the four meta-analyses and 23 trials did not appear in more than one meta-analysis. ${ }^{28,32,35,54,66-68}$

our out of five meta-analyses $(80 \%)$ found that antidepressants could prevent PSD and improve depression rating scores. Two meta-analyses, using English and Chinese language databases, focused on the effects of sertraline and other antidepressants in the treatment and prevention of PSD. One of these meta-analyses synthesized data from nine trials. The results of these analyses suggested that sertraline is effective for PSD prevention by reducing depression rating scores and 
Table 5 Study Quality

\begin{tabular}{|c|c|c|c|c|c|}
\hline Reference & Year & Country & Study Design & Jadad Scale & Study Quality \\
\hline \multicolumn{6}{|c|}{ Studies of Antidepressants for Prevention of PSD } \\
\hline Niedermaier ${ }^{27}$ & 2004 & Germany & RCT & 2 & Poor \\
\hline Tsai $^{28}$ & 2011 & Taiwan & RCT & 4 & High \\
\hline Almeida $^{30}$ & 2006 & Australia & RCT & $\mathrm{N} / \mathrm{A}$ & N/A \\
\hline Rasmussen $^{31}$ & 2003 & Denmark & RCT & 3 & High \\
\hline $\mathrm{Kim}^{32}$ & 2017 & South Korea & RCT & 5 & High \\
\hline Palomäki ${ }^{33}$ & 1999 & Finland & RCT & 4 & High \\
\hline FOCUS Trial Collaboration ${ }^{34}$ & 2019 & UK & RCT & 5 & High \\
\hline Zhang $^{35}$ & 2013 & China & RCT & 2 & Poor \\
\hline $\mathrm{CaO}^{36}$ & 2020 & China & RCT & 2 & Poor \\
\hline AFFINITY Trial Collaboration ${ }^{29}$ & 2020 & Australia, New Zealand, Vietnam & RCT & 5 & High \\
\hline EFFECTS Trial Collaboration ${ }^{37}$ & 2020 & Sweden & RCT & 3 & High \\
\hline \multicolumn{6}{|c|}{ Studies of Non-Pharmacological Approaches for Prevention of PSD } \\
\hline Zhang $^{38}$ & 2019 & China & RCT & 3 & High \\
\hline $\mathrm{Lai}^{39}$ & 2006 & USA & RCT & 3 & High \\
\hline Jönsson ${ }^{46}$ & 2014 & Sweden & RCT & 3 & High \\
\hline Boter $^{47}$ & 2004 & Netherlands & RCT & 3 & High \\
\hline Rochette $^{48}$ & 2013 & Canada & RCT & 2 & Poor \\
\hline Joubert $^{49}$ & 2008 & Australia & RCT & 2 & Poor \\
\hline Sajatovic ${ }^{50}$ & 2018 & USA & RCT & 2 & Poor \\
\hline Gillham $^{51}$ & 2010 & UK & RCT & 3 & High \\
\hline Ihle-Hansen ${ }^{52}$ & 2019 & Norway & RCT & $\mathrm{I}$ & Poor \\
\hline Cheng $^{53}$ & 2018 & China & RCT & 3 & High \\
\hline Hackett $^{40}$ & 2013 & Australia & RCT & 3 & High \\
\hline Faulkner ${ }^{41}$ & 2015 & New Zealand & RCT & 3 & High \\
\hline Ihle-Hansen ${ }^{42}$ & 2014 & Norway & RCT & 3 & High \\
\hline Kang $^{43}$ & 2009 & South Korea & $\mathrm{RCT}$ & 2 & Poor \\
\hline Kirk $^{44}$ & 2014 & UK & RCT & 3 & High \\
\hline Davis $^{45}$ & 2004 & USA & $\mathrm{RCT}$ & 2 & Poor \\
\hline \multicolumn{6}{|c|}{ Studies of Multimodal Strategies for Prevention of PSD } \\
\hline Robinson $^{54}$ & 2008 & USA & RCT & 5 & High \\
\hline Hoffmann ${ }^{55}$ & 2015 & Australia & $\mathrm{RCT}$ & 3 & High \\
\hline Mikami $^{56}$ & 2011 & USA & RCT (follow-up) & N/A & $\mathrm{N} / \mathrm{A}$ \\
\hline Hill $^{57}$ & 2019 & UK & RCT & 3 & High \\
\hline Narushima $^{58}$ & 2002 & USA & RCT & 4 & High \\
\hline
\end{tabular}

Abbreviation: RCT, randomized controlled trial.

decreasing the incidence of PSD compared to control groups, with a risk ratio of 0.48 at the end of treatment. ${ }^{59}$ The other meta-analysis, which included a Chinese database search, comprised 12 trials on nortriptyline, fluoxetine, sertraline, escitalopram, milnacipran, duloxetine, and paroxetine. In this pooled analysis, the use of an antidepressant was associated with a decreased incidence of PSD and alleviation of depressive symptoms. ${ }^{60}$ In another meta-analysis, data from seven studies on PSD prevention using fluoxetine, sertraline, escitalopram, mianserin, and duloxetine were synthesized. Pooled analysis confirmed the efficacy of antidepressants in preventing PSD. ${ }^{61}$ Two meta-analyses pooled data on early initiation of SSRI treatment using fluoxetine, sertraline, escitalopram, or citalopram within 30 days after stroke onset. One of these analyses reported that the administration of SSRIs showed no association with the risk of PSD, based on pooled data from three RCTs. ${ }^{62}$ Around 2 years later, an updated meta-analysis of synthesized data from four trials found that stroke survivors receiving SSRIs have a decreased risk of PSD (risk ratio $0.78)^{63}$ 
The identified meta-analyses on PSD prevention are detailed in Table 6.

\section{Discussion}

This updated systematic review identified a substantial body of research on the use of antidepressants and nonpharmacological interventions to prevent PSD, comprising 37 prospective interventional studies, the majority of them conducted in the USA, China, Australia, and the UK. However, partially conflicting results due to heterogeneity in study designs and methodology may limit the external validity of the findings.
In a recent scientific statement for healthcare professionals from the American Heart Association/American Stroke Association, Towfighi et al declared that pharmacotherapy and psychosocial interventions might be useful in the prevention of PSD, but further research is needed to determine the optimal timing, threshold, and medications for treatment. ${ }^{11}$ Although we found evidence on antidepressive pharmacotherapy as a tertiary preventive measure for PSD after stroke, designing personalized pharmacological prevention strategies of PSD may additionally benefit from previous research on the treatment of manifest PSD. However, there are also inconsistencies in the evidence on

Table 6 Meta-Analytic Evidence on Strategies to Prevent PSD

\begin{tabular}{|c|c|c|c|c|c|c|c|}
\hline Reference & Country & $\begin{array}{l}\text { Database } \\
\text { Source }\end{array}$ & $\begin{array}{l}\text { Study } \\
\text { Design }\end{array}$ & $\begin{array}{l}\text { No. of } \\
\text { Studies } \\
\text { (Patients); } \\
\text { Recruitment } \\
\text { After Stroke }\end{array}$ & $\begin{array}{l}\text { Data } \\
\text { Range }\end{array}$ & Study Approach & Outcome \\
\hline Feng $^{59}$ & China & $\begin{array}{l}\text { PubMed, } \\
\text { Embase, } \\
\text { Scopus, } \\
\text { CENTRAL, } \\
\text { Clinicaltrials. } \\
\text { gov, Wanfang } \\
\text { Data, VIP, } \\
\text { CNKI }\end{array}$ & RCTs & $\begin{array}{l}\text { II (I258); Not } \\
\text { specified }\end{array}$ & $\begin{array}{l}\text { Inception to } \\
\text { April } 2017\end{array}$ & SSRI: sertraline & $\begin{array}{l}\text { Data from } 6 \text { pooled studies suggested } \\
\text { a significant advantage of sertraline vs placebo } \\
\text { based on depression rating scores (WMD } \\
-6.38 ; 95 \% \mathrm{Cl}-8.63 \text { to }-4.14 ; P<0.0000 \mathrm{I} ; I^{2} \\
84.0 \% \text { ). Data from } 3 \text { pooled studies suggested } \\
\text { a significant reduced risk of PSD in sertraline } \\
\text { groups vs placebo (RR } 0.48 ; 95 \% \mathrm{Cl} 0.35 \text { to } \\
0.67 ; P<0.000 \mathrm{I} ; I^{2} 34.0 \% \text { ) }\end{array}$ \\
\hline \multirow[t]{2}{*}{$\mathrm{Gu}^{60}$} & \multirow[t]{2}{*}{ China } & \multirow{2}{*}{$\begin{array}{l}\text { PubMed, } \\
\text { Embase, } \\
\text { Scopus, } \\
\text { CENTRAL, } \\
\text { Wanfang Data, } \\
\text { VIP, CNKI }\end{array}$} & \multirow[t]{2}{*}{ RCTs } & \multirow[t]{2}{*}{$\begin{array}{l}\text { I2 (1257); Not } \\
\text { specified }\end{array}$} & \multirow[t]{2}{*}{$\begin{array}{l}\text { Inception to } \\
\text { June } 9,2019\end{array}$} & \multirow{2}{*}{$\begin{array}{l}\text { Antidepressive drugs: } \\
\text { nortriptyline, } \\
\text { fluoxetine, sertraline, } \\
\text { escitalopram, } \\
\text { milnacipran, } \\
\text { duloxetine, } \\
\text { paroxetine }\end{array}$} & $\begin{array}{l}\text { Data from } 2 \text { pooled studies suggested } \\
\text { a significant advantage of antidepressants vs } \\
\text { placebo based on HAM-D (MD }-5.73 ; 95 \% \mathrm{Cl} \\
-7.29 \text { to }-4.18 ; \text { P }<0.00 \text { I) }\end{array}$ \\
\hline & & & & & & & $\begin{array}{l}\text { Data from } 12 \text { pooled studies suggested } \\
\text { a significant reduced risk of PSD in } \\
\text { antidepressant groups vs placebo (RR } 0.33 \text {; } \\
95 \% \mathrm{Cl} 0.25 \text { to } 0.43 ; P<0.00 \mathrm{I} \text { ) }\end{array}$ \\
\hline Farooq $^{61}$ & UK & $\begin{array}{l}\text { PubMed, } \\
\text { PsycINFO, } \\
\text { Embase, } \\
\text { CINHAL }\end{array}$ & RCTs & $\begin{array}{l}28 \text { (2745); Not } \\
\text { specified }\end{array}$ & $\begin{array}{l}\text { I } 980 \text { to } \\
\text { January } 2020\end{array}$ & $\begin{array}{l}\text { Antidepressive drugs: } \\
\text { fluoxetine, sertraline, } \\
\text { escitalopram, } \\
\text { mianserin, duloxetine }\end{array}$ & $\begin{array}{l}\text { Data from } 7 \text { pooled studies suggested } \\
\text { a significant reduced risk of PSD in } \\
\text { antidepressant groups vs placebo (OR } 0.16 \text {; } \\
95 \% \mathrm{Cl} 0.05 \text { to } 0.55 \text { ) }\end{array}$ \\
\hline $\mathrm{Gu}^{62}$ & China & $\begin{array}{l}\text { PubMed, } \\
\text { Embase, } \\
\text { Cochrane } \\
\text { Library }\end{array}$ & RCTs & $\begin{array}{l}8(1549) ;<1 \\
\text { mo }\end{array}$ & $\begin{array}{l}\text { Inception to } \\
\text { January } 2017\end{array}$ & $\begin{array}{l}\text { Early SSRI treatment: } \\
\text { fluoxetine, sertraline, } \\
\text { escitalopram, } \\
\text { citalopram }\end{array}$ & $\begin{array}{l}\text { No difference: } 3 \text { pooled studies suggested no } \\
\text { significant reduced risk of PSD in early SSRIs vs } \\
\text { placebo (RR } 0.7 I \text {; } 95 \% \text { Cl } 0.4 I \text { to I.23; } P=0.52 \text {; } \\
I^{2} 48 \% \text { ) }\end{array}$ \\
\hline Zhou $^{63}$ & China & $\begin{array}{l}\text { PubMed, } \\
\text { Embase, } \\
\text { Cochrane } \\
\text { Library, } \\
\text { MEDLINE }\end{array}$ & RCTs & $\begin{array}{l}10(5370) ;<1 \\
\text { mo }\end{array}$ & $\begin{array}{l}\text { Inception to } \\
\text { March 18, } \\
2019\end{array}$ & $\begin{array}{l}\text { Early SSRI treatment: } \\
\text { fluoxetine, sertraline, } \\
\text { escitalopram, } \\
\text { citalopram }\end{array}$ & $\begin{array}{l}\text { Data from } 4 \text { pooled studies suggested } \\
\text { a significant reduced risk of PSD in SSRIs vs } \\
\text { placebo (RR } 0.78 ; 95 \% \mathrm{Cl} 0.67 \text { to } 0.90 \text {; } \\
P=0.00 \mathrm{I} ; I^{2} 23 \% \text { ) }\end{array}$ \\
\hline
\end{tabular}

Abbreviations: WMD, weighted mean difference; $\mathrm{Cl}$, confidence interval; $\mathrm{RR}$, risk ratio; $I^{2}$, percentage of variation across studies. 
prevention versus treatment of PSD, which may indicate differences in the underlying pathophysiology. For instance, meta-analytic evidence suggests that paroxetine may be more efficacious than the more widely used alternatives, fluoxetine and nortriptyline. ${ }^{21,22}$ However, we identified no reports on the effect of paroxetine in PSD prevention in our review. It is noteworthy that common side effects of most antidepressants are dry mouth, drowsiness, constipation, and nausea. These adverse effects were more pronounced and less well tolerated for citalopram, duloxetine, fluoxetine, and sertraline compared with doxepin, nortriptyline, and paroxetine. ${ }^{21}$ In the FOCUS and EFFECTS studies, a higher number of bone fractures was observed after 6 months than in the control group (FOCUS: $2.88 \%$ vs $1.47 \%$, 95\% CI $0.38-2.43 ; P=0.007$; EFFECTS: $4 \%$ vs $2 \%, 95 \%$ CI $0.66-3.87 ; P=0.0058$ ). In addition, more frequent hyponatremia (EFFECTS: $1 \%$ vs $<1 \%, 95 \%$ CI $0.43-2.23 ; P=0.0038)$, and a more frequent occurrence of falls (AFFINITY: $3 \%$ vs $1 \% ; P=0.018$ ) and epileptic seizures (AFFINITY: $2 \%$ vs $<1 \% ; P=0.038$ ) were reported in the fluoxetine group compared with placebo. $^{29,34,37}$ Consequently, before prescribing antidepressant therapy to prevent PSD, a risk-benefit analysis should be carried out and interactions in case of polypharmacy should be considered. Early application of fluoxetine after stroke demonstrated a preventive role for PSD in short-term usage and had no side effects during or after the treatment period. ${ }^{69,70}$ However, nortriptyline-treated patients, ${ }^{58}$ as well as those receiving escitalopram, ${ }^{56}$ showed increased depression symptoms following the termination of treatment 6 months later compared to those receiving fluoxetine and placebo. In one of the studies, the control group of stroke survivors did not develop any PSD at all, limiting the comparability of results between the active group (antidepressive pharmacotherapy) and the control group. ${ }^{33}$

To date, clinical trials have focused on PSD prevention by harmonizing the interaction between physical and psychological systems as well as by educating stroke patients. ${ }^{71}$ Therefore, educational and physical health support strategies have frequently been used as the intervention in studies on both the prevention and treatment of PSD. In fact, research has shown that by educating patients about the pathology of stroke, they can recover more quickly and can handle the illness better in rehabilitation in hospital or at home..$^{38,42,49,72}$ This observation, viewed in conjunction with existing evidence on pharmacological and therapeutic non-pharmacological PSD prevention, substantiates a need for integrative, personalized strategies. In integrative prevention strategies, it may be an important piece of the puzzle that PSD patients acknowledge their situation and know how to handle and overcome the sickness with support from healthcare specialists as well as relatives. This also explains why distant and occasional support strategies were found to be unlikely to contribute toward preventing PSD. $^{40,51,73}$ However, a comprehensive rehabilitation program showed promising results in preventing PSD and decreased cognitive impairment. ${ }^{53}$ On a mechanistic level, this observation introduces the possibility of another complementary technique that may be helpful in multimodal integrative prevention measures in patients after acute stroke. Exercisebased interventions did not show a clear effect on PSD prevention, independently of whether they were applied as short- or long-term treatment. However, the time-point of initiating exercise protocols may be more important than the duration; for example, very early mobilization within 24 hours of stroke was shown to be potentially beneficial in the prevention of PSD in the early stage. ${ }^{74}$ The intervention may be of additional use in the retraining of paretic muscles as well as in the improvement of cognitive functions after stroke..$^{50,75,76}$

While prevention of PSD is of high clinical importance, treatment of manifest PSD is equally challenging and often requires pharmacological intervention. A systematic Cochrane Collaboration review article, published in 2020, included 18 RCTs and compared 20 pharmacological substances with placebo with regard to remission of PSD over time. Different antidepressants were used, most commonly SSRIs [fluoxetine $(n=6)$, paroxetine $(n=3)$, citalopram $(n=2)$, sertraline $(n=1)]$, as well as amitriptyline $(\mathrm{n}=1)$, nortriptyline $(\mathrm{n}=1)$, deanxit $(\mathrm{n}=1)$, nefiracetam $(n=2)$, aniracetam $(n=1)$, reboxetine $(n=1)$, and trazodone $(n=1)$. The time-point of initiation of antidepressive treatment post-stroke varied across studies, between a few days and 25 months. Duration of treatment also varied across trials, ranging between a few weeks and 6 months. Patients with PSD at the time of study inclusion who subsequently received antidepressant therapy showed a 30\% lower risk of developing PSD at the end of treatment compared to PSD patients without antidepressant therapy (risk ratio $00.7 ; 95 \%$ CI $0.55-0.88$ ). ${ }^{77}$

There are several proposed mechanisms through which antidepressants could have beneficial effects on ischemic brain tissue and, in turn, potentially reduce the risk of 
depression caused by structural and functional brain changes. These mechanisms derived from animal research on SSRIs. ${ }^{78-83}$ It was observed that the administration of SSRIs after stroke may enhance neuroplasticity by facilitating neurogenesis in the ventricular subependyma and the subgranular area of the hippocampal dentate gyrus, and may mediate neuroprotection via attenuation of inflammatory pathways, such as the activation of microglia and neutrophil granulocytes. Moreover, the improvement of cerebral blood flow regulation by normalizing the lower boundary of cerebral mean arterial pressure and increasing the expression of heme oxygenase-1, with subsequent production of carbon monoxide, was suggested to be mediated by SSRIs after stroke. Lastly, upregulation of beta- 1 receptors in the caudate-putamen and the somatosensory parts of the frontal cortex was observed in rats receiving citalopram or fluoxetine, but it remained unclear how this might benefit ischemic brain tissue.

Our initial focus was to undertake a review of RCTs. Since several meta-analyses pooled data from multiple RCTs, we decided to include these pooled analyses in our review as they potentially add additional observations and conclusions to our review beyond the scope of singular RCTs. We did not include any systematic reviews that did not synthesize data from RCTs, as those articles would not have added any new data-driven conclusions.

Our review is limited by the methodological heterogeneity of the included studies. Numerous studies use various depression survey instruments, thus complicating a comparison of the studies. In addition, the diagnosis of depression was often defined on the basis of fixed values in the survey instruments and psychiatric interviews were not usually carried out to establish the diagnosis. The short observation period of most studies has to be considered critically. Not much is known about the long-term benefits of antidepressant therapy for the prevention of PSD. In many studies, the results of both patients with ischemic stroke and those with hemorrhagic stroke were evaluated together, but the postulated mechanisms of SSRIs relate only to ischemic stroke. Further, it remains a challenge for future studies to differentiate between PSD after ischemic and hemorrhagic stroke to test preventive strategies. A severe neurological deficit is associated with the development of PSD. Therefore, studies that only include slightly affected patients could have been associated with bias. However, the systematic review methodology, following PRISMA guidelines, and the detailed characterization of the included studies allowed an overview of the literature and substantiated our main conclusion, the apparent need for well-designed confirmatory research in large cohorts of stroke survivors on primary preventive pharmacological and non-pharmacological strategies to reduce the risk of PSD and thus improve clinical outcomes in this vulnerable population of patients.

\section{Conclusion}

Our systematic review provides a summary of the current knowledge on PSD prevention. The current body of evidence on interventions to prevent PSD shows substantial heterogeneity. This observation substantiates a need for well-designed randomized controlled trials to test the safety and efficacy of pharmacological as well as non-pharmacological and composite prevention regimens to minimize the risk of PSD in stroke survivors.

From a clinician's point of view, the given data suggest that integrative strategies combining personalized non-pharmacological interventions such as educational, mental and physical health support, and pharmacological strategies such as SSRIs may be the most promising approach. However, despite the lack of clear statistical evidence, such an integrative approach relies on the local feasibility and clinical environment.

\section{Disclosure}

Dr. Siepmann and Dr. Barlinn are editorial board members of Neuropsychiatric Disease and Treatment (unpaid position). The authors report no conflicts of interest for this work and declare that the review was conducted in the absence of any commercial or financial relationships that could be construed as a potential conflict of interest.

\section{References}

1. Strong K, Mathers C, Bonita R. Preventing stroke: saving lives around the world. Lancet Neurol. 2007;6(2):182-187.

2. Winstein CJ, Stein J, Arena R, et al. Guidelines for adult stroke rehabilitation and recovery. Stroke. 2016;47(6):e98-e169.

3. Hackett ML, Yapa C, Parag V, Anderson CS. Frequency of depression after stroke: a systematic review of observational studies. Stroke. 2005;36(6):1330-1340. doi:10.1161/01.STR.0000165928.19135.35

4. Hackett ML, Pickles K. Part I: frequency of depression after stroke: an updated systematic review and meta-analysis of observational studies. Int J Stroke. 2014;9(8):1017-1025. doi:10.1111/ijs.12357

5. American Psychiatric Association. American Psychiatric Association: Diagnostic and Statistical Manual of Mental Disorders. Fifth ed. Arlington; 2013.

6. Robinson RG, Jorge RE. Post-stroke depression: a review. Am J Psychiatry. 2016;173(3):221-231. doi:10.1176/appi.ajp.2015.15030363

7. Robinson RG, Price TR. Post-stroke depressive disorders: a follow-up study of 103 patients. Stroke. 1982;13(5):635-641. doi:10.1161/01. STR.13.5.635 
8. Robinson RG, Starr LB, Kubos KL, Price TR. A two-year longitudinal study of post-stroke mood disorders: findings during the initial evaluation. Stroke. 1983;14(5):736-741. doi:10.1161/01. STR.14.5.736

9. Kim DY, Park HS, Park SW, Kim JH. The impact of dysphagia on quality of life in stroke patients. Medicine (Baltimore). 2020;99(34) e21795. doi:10.1097/MD.0000000000021795

10. Jaracz K, Jaracz J, Kozubski W, Rybakowski JK. Post-stroke quality of life and depression. Acta Neuropsychiatr. 2002;14(5):219-225. doi:10.1034/j.1601-5215.2002.140504.x

11. Towfighi A, Ovbiagele B, El Husseini N, et al. Poststroke depression: a scientific statement for healthcare professionals from the American Heart Association/American Stroke Association. Stroke. 2017;48(2) e30-43. doi:10.1161/STR.0000000000000113

12. Husaini B, Levine R, Sharp L, et al. Depression increases stroke hospitalization cost: an analysis of 17,010 stroke patients in 2008 by race and gender. Stroke Res Treat. 2013;2013:846732.

13. Babkair LA. Risk factors for poststroke depression: an integrative review. $J$ Neurosci Nurs. 2017;49(2):73-84. doi:10.1097/ JNN.0000000000000271

14. Shi Y, Yang D, Zeng Y, Wu W. Risk factors for post-stroke depression: a meta-analysis. Front Aging Neurosci. 2017;9:218. doi:10.3389/fnagi.2017.00218

15. Ilut S, Stan A, Blesneag A, Vacaras V, Vesa S, Fodoreanu L. Factors that influence the severity of post-stroke depression. J Med Life. 2017;10(3):167-171

16. Wei N, Yong W, Li X, et al. Post-stroke depression and lesion location: a systematic review. $J$ Neurol. 2015;262(1):81-90. doi:10.1007/s00415-014-7534-1

17. Barlinn K, Kepplinger J, Puetz V, Illigens BM, Bodechtel U, Siepmann T. Exploring the risk-factor association between depression and incident stroke: a systematic review and meta-analysis. Neuropsychiatr Dis Treat. 2014;11:1-14. doi:10.2147/NDT.S63904

18. Eastwood MR, Rifat SL, Nobbs H, Ruderman J. Mood disorder following cerebrovascular accident. $\mathrm{Br} J$ Psychiatry. 1989;154:195-200. doi:10.1192/bjp.154.2.195

19. Carota A, Bogousslavsky J. Mood disorders after stroke. Front Neurol Neurosci. 2012;30:70-74.

20. Folstein MF, Maiberger R, Mchugh PR. Mood disorder as a specific complication of stroke. J Neurol Neurosurg Psychiatry. 1977;40 (10):1018-1020. doi:10.1136/jnnp.40.10.1018

21. Sun Y, Liang Y, Jiao Y, et al. Comparative efficacy and acceptability of antidepressant treatment in poststroke depression: a multiple-treatments meta-analysis. BMJ Open. 2017;7(8):1-10. doi:10.1136/bmjopen-2017-016499

22. Qin B, Chen H, Gao W, et al. Efficacy, acceptability, and tolerability of antidepressant treatments for patients with post-stroke depression: a network meta-analysis. Braz J Med Biol Res. 2018;51(7):1-11. doi:10.1590/1414-431x20187218

23. Ramasubbu R. Therapy for prevention of post-stroke depression. Expert Opin Pharmacother. 2011;12(14):2177-2187. doi:10.1517/ 14656566.2011.596149

24. Lee Y, Chen B, Fong MWM, et al. Effectiveness of non-pharmacological interventions for treating post-stroke depressive symptoms: systematic review and meta-analysis of randomized controlled trials. Top Stroke Rehabil. 2021;28(4):289-320. doi:10.1080/ 10749357.2020.1803583

25. Moher D, Liberati A, Tetzlaff J, Altman DG, Altman D; PRISMA group. Preferred reporting items for systematic reviews and meta-analyses: the PRISMA statement. Ann Intern Med. 2009;151 (4):264. doi:10.7326/0003-4819-151-4-200908180-00135

26. Lanctôt KL, Lindsay MP, Smith EE, et al. Canadian stroke best practice recommendations: mood, cognition and fatigue following stroke, 6th edition update 2019. Int J Stroke. 2020;15(6):668. doi:10.1177/1747493019847334
27. Niedermaier N, Bohrer E, Schulte K, Schlattmann P, Heuser I. Prevention and treatment of poststroke depression with mirtazapine in patients with acute stroke. J Clin Psychiatry. 2004;65 (12):1619-1623. doi:10.4088/JCP.v65n1206

28. Tsai CS, Wu CL, Chou SY, Tsang HY, Hung TH, Su JA. Prevention of poststroke depression with milnacipran in patients with acute ischemic stroke: a double-blind randomized placebo-controlled trial. Int Clin Psychopharmacol. 2011;26:263-267. doi:10.1097/ YIC.0b013e32834a5c64

29. Hankey GJ, Hackett ML, Almeida OP, et al. Safety and efficacy of fluoxetine on functional outcome after acute stroke (AFFINITY): a randomised, double-blind, placebo-controlled trial. Lancet Neurol. 2020;19(8):651-660. doi:10.1016/S1474-4422(20)30207-6

30. Almeida OP, Waterreus A, Hankey GJ. Preventing depression after stroke: results from a randomized placebo-controlled trial. J Clin Psychiatry. 2006;67:1104-1109. doi:10.4088/JCP.v67n0713

31. Rasmussen A, Lunde M, Poulsen DL, Sørensen K, Qvitzau S, Bech P. A double-blind, placebo-controlled study of sertraline in the prevention of depression in stroke patients. Psychosomatics. 2003;44(3):216-221. doi:10.1176/appi.psy.44.3.216

32. Kim JS, Lee EJ, Chang DI, et al. Efficacy of early administration of escitalopram on depressive and emotional symptoms and neurological dysfunction after stroke: a multicentre, double-blind, randomised, placebo-controlled study. Lancet Psychiatr. 2017;4(1):33-41. doi:10.1016/S2215-0366(16)30417-5

33. Palomäki H, Kaste M, Berg A, et al. Prevention of poststroke depression: 1 year randomised placebo controlled double blind trial of mianserin with 6 month follow up after therapy. $J$ Neurol Neurosurg Psychiatry. 1999;66:490-494. doi:10.1136/jnnp.66.4.490

34. FOCUS Trial Collaboration. Effects of fluoxetine on functional outcomes after acute stroke (FOCUS): a pragmatic, double-blind, randomised, controlled trial. Lancet. 2019;393(10168):265-274.

35. Zhang LS, Hu XY, Yao LY, et al. Prophylactic effects of duloxetine on post-stroke depression symptoms: an open single-blind trial. Eur Neurol. 2013;69(6):336-343. doi:10.1159/000345374

36. Cao JX, Liu L, Sun YT, Zeng QH, Wang Y, Chen JC. Effects of the prophylactic use of escitalopram on the prognosis and the plasma copeptin level in patients with acute cerebral infarction. Brazi J Med Biol Res. 2020;53(11):e8930. doi:10.1590/1414-431×20208930

37. Lundström E, Isaksson E, Näsman P, et al. Safety and efficacy of fluoxetine on functional recovery after acute stroke (EFFECTS): a randomised, double-blind, placebo-controlled trial. Lancet Neurol. 2020;19(8):661-669. doi:10.1016/S1474-4422(20)30219-2

38. Zhang L, Zhang T, Sun Y. A newly designed intensive caregiver education program reduces cognitive impairment, anxiety, and depression in patients with acute ischemic stroke. Brazi J Med Biol Res. 2019;52(9):e8533. doi:10.1590/1414-431×20198533

39. Lai SM, Studenski S, Richards L, et al. Therapeutic exercise and depressive symptoms after stroke. J Am Geriatr Soc. 2006;54 (2):240-247. doi:10.1111/j.1532-5415.2006.00573.x

40. Hackett ML, Carter G, Crimmins D, et al. ImProving Outcomes after STroke (POST): results from the randomized clinical pilot trial. Int J Stroke. 2013;8:707-710. doi:10.1111/j.1747-4949.2012.00913.x

41. Faulkner J, McGonigal G, Woolley B, Stoner L, Wong L, Lambrick D. A randomized controlled trial to assess the psychosocial effects of early exercise engagement in patients diagnosed with transient ischaemic attack and mild, non-disabling stroke. Clin Rehabil. 2015;29(8):783-794. doi:10.1177/0269215514555729

42. Ihle-Hansen H, Thommessen B, Fagerland MW, et al. Effect on anxiety and depression of a multifactorial risk factor intervention program after stroke and TIA: a randomized controlled trial. Aging Ment Health. 2014;18:540-546. doi:10.1080/13607863.2013.824406

43. Kang HS, Sok SR, Kang JS. Effects of Meridian acupressure for stroke patients in Korea. J Clin Nurs. 2009;18:2145-2152. doi:10.1111/j.1365-2702.2008.02522.x 
44. Kirk H, Kersten P, Crawford P, Keens A, Ashburn A, Conway J. The cardiac model of rehabilitation for reducing cardiovascular risk factors post transient ischaemic attack and stroke: a randomized controlled trial. Clin Rehabil. 2014;28:339-349. doi:10.1177/0269215513502211

45. Davis MC. Life review therapy as an intervention to manage depression and enhance life satisfaction in individuals with right hemisphere cerebral vascular accidents. Issues Ment Health Nurs. 2004;25:503-515. doi:10.1080/01612840490443455

46. Jönsson AC, Höglund P, Brizzi M, Pessah-Rasmussen H. Secondary prevention and health promotion after stroke: can it be enhanced? J Stroke Cerebrovasc Dis. 2014;23:2287-2295. doi:10.1016/j. jstrokecerebrovasdis.2014.04.021

47. Boter H. Multicenter randomized controlled trial of an outreach nursing support program for recently discharged stroke patients. Stroke. 2004;35:2867-2872. doi:10.1161/01.STR.0000147717.5 7531.e5

48. Rochette A, Korner-Bitensky N, Bishop D, et al. The YOU CALL-WE CALL randomized clinical trial: impact of a multimodal support intervention after a mild stroke. Circ Cardiovasc Qual Outcomes. 2013;6:674-679. doi:10.1161/CIRCOUTCOMES.113.000375

49. Joubert J, Joubert L, Reid C, et al. The positive effect of integrated care on depressive symptoms in stroke survivors. Cerebrovasc Dis. 2008;26:199-205. doi:10.1159/000145328

50. Sajatovic M, Tatsuoka C, Welter E, et al. A targeted self-management approach for reducing stroke risk factors in African American men who have had a stroke or transient ischemic attack. Am J Health Promot. 2018;32:282-293. doi:10.1177/0890117117695218

51. Gillham S, Endacott R. Impact of enhanced secondary prevention on health behaviour in patients following minor stroke and transient ischaemic attack: a randomized controlled trial. Clin Rehabil. 2010;24:822-830. doi:10.1177/0269215510367970

52. Ihle-Hansen $\mathrm{H}$, Langhammer $\mathrm{B}$, Lydersen S, Gunnes $\mathrm{M}$, Indredavik B, Askim T. A physical activity intervention to prevent cognitive decline after stroke: secondary results from the Life After STroke study, an 18-month randomized controlled trial. J Rehabil Med. 2019;51:646-651. doi:10.2340/16501977-2588

53. Cheng C, Liu X, Fan W, Bai X, Liu Z. Comprehensive rehabilitation training decreases cognitive impairment, anxiety, and depression in poststroke patients: a randomized, controlled study. J Stroke Cerebrovasc Dis. 2018;27:2613-2622. doi:10.1016/j. jstrokecerebrovasdis.2018.05.038

54. Robinson RG, Jorge RE, Moser DJ, et al. Escitalopram and problem-solving therapy for prevention of poststroke depression: a randomized controlled trial. JAMA. 2008;299(20):2391-2400. doi:10.1001/jama.299.20.2391

55. Hoffmann T, Ownsworth T, Eames S, Shum D. Evaluation of brief interventions for managing depression and anxiety symptoms during early discharge period after stroke: a pilot randomized controlled trial. Top Stroke Rehabil. 2015;22(2):116-126. doi:10.1179/ 1074935714Z.0000000030

56. Mikami K, Jorge RE, Moser DJ, et al. Increased frequency of first-episode poststroke depression after discontinuation of escitalopram. Stroke. 2011;42:3281-3283. doi:10.1161/ STROKEAHA.111.626507

57. Hill K, House A, Knapp P, Wardhaugh C, Bamford J, Vail A. Prevention of mood disorder after stroke: a randomised controlled trial of problem solving therapy versus volunteer support. $B M C$ Neurol. 2019;19(1):1-10. doi:10.1186/s12883-019-1349-8

58. Narushima K, Kosier JT, Robinson RG. Preventing poststroke depression: a 12-week double-blind randomized treatment trial and 21-month follow-up. J Nerv Ment Dis. 2002;190:296-303. doi:10.1097/00005053-200205000-00005

59. Feng R, Wang P, Gao C, et al. Effect of sertraline in the treatment and prevention of poststroke depression A meta-analysis. Medicine (Baltimore). 2018;97(49):1-11. doi:10.1097/MD.0000000000013453
60. Gu J, Huang H, Chen K, Huang G, Huang Y, Xu H. Are they necessary? Preventive therapies for post-stroke depression: a meta-analysis of RCTs. Psychiatry Res. 2020;284:112670. doi:10.1016/j.psychres.2019.112670

61. Farooq S, Singh SP, Burke D, Naeem F, Ayub M. Pharmacological interventions for prevention of depression in high risk conditions: systematic review and meta-analysis. $J$ Affect Disord. 2020;269:58-69. doi:10.1016/j.jad.2020.03.024

62. Gu SC, De Wang C. Early selective serotonin reuptake inhibitors for recovery after stroke: a meta-analysis and trial sequential analysis. J Stroke Cerebrovasc Dis. 2018;27(5):1178-1189. doi:10.1016/j. jstrokecerebrovasdis.2017.11.031

63. Zhou S, Liu S, Liu X, Zhuang W. Selective serotonin reuptake inhibitors for functional Independence and depression prevention in early stage of post-stroke: a meta-analysis. Medicine (Baltimore). 2020;99(6):1-8.

64. Chollet F, Tardy J, Albucher JF, et al. Fluoxetine for motor recovery after acute ischaemic stroke (FLAME): a randomised placebo-controlled trial. Lancet Neurol. 2011;10(2):123-130. doi:10.1016/S1474-4422(10)70314-8

65. Kraglund KL, Mortensen JK, Damsbo AG, et al. Neuroregeneration and vascular protection by Citalopram in acute ischemic stroke (TALOS) A randomized controlled study. Stroke. 2018;49 (11):2568-2576. doi:10.1161/STROKEAHA.117.020067

66. Savadi Oskouie D, Sharifipour E, Sadeghi Bazargani H, et al. Efficacy of citalopram on acute ischemic stroke outcome: a randomized clinical trial. Neurorehabil Neural Repair. 2017;31 (7):638-647. doi:10.1177/1545968317704902

67. Guo Y, He Y, Tang B, et al. Effect of using fluoxetine at different time windows on neurological functional prognosis after ischemic stroke. Restor Neurol Neurosci. 2016;34(2):177-187.

68. He YT, Tang BS, Cai ZL, Zeng SL, Jiang X, Guo Y. Effects of fluoxetine on neural functional prognosis after ischemic stroke: a randomized controlled study in China. J Stroke Cerebrovasc Dis. 2016;25(4):761-770. doi:10.1016/j.jstrokecerebrovasdis.20 15.11.035

69. Fruehwald S, Gatterbauer E, Rehak P, Baumhackl U. Early fluoxetine treatment of post-stroke depression: a three-month double-blind placebo-controlled study with an open-label long-term follow up. J Neurol. 2003;250(3):347-531. doi:10.1007/s00415-003-1014-3

70. Wiart L, Petit H, Joseph PA, Mazaux JM, Barat M. Fluoxetine in early poststroke depression: a double-blind placebo-controlled study. Stroke. 2000;31(8):1829-1832. doi:10.1161/01.STR.31.8.1829

71. Bilge C, Koçer E, Koçer A, Börü ÜT. Depression and functional outcome after stroke: the effect of antidepressant therapy on functional recovery. Eur J Phys Rehabil Med. 2008;44(1):13-18.

72. Graven C, Brock K, Hill KD, Cotton S, Joubert L. First year after stroke: an integrated approach focusing on participation goals aiming to reduce depressive symptoms. Stroke. 2016;47(11):2820-2827. doi:10.1161/STROKEAHA.116.013081

73. Kerr D, McCann T, Mackey E, Wijeratne T. Effects of early motivational interviewing on post-stroke depressive symptoms: a pilot randomized study of the good mood intervention program. Int J Nurs Pract. 2018;24(4):1-8. doi:10.1111/ijn.12657

74. Cumming TB, Collier J, Thrift AG, Bernhardt J. The effect of very early mobilization after stroke on psychological well-being. $J$ Rehabil Med. 2008;40(8):609-614. doi:10.2340/16501977-0226

75. Vahlberg B, Cederholm T, Lindmark B, Zetterberg L, Hellström K. Short-term and long-term effects of a progressive resistance and balance exercise program in individuals with chronic stroke: a randomized controlled trial. Disabil Rehabil. 2017;39 (16):1615-1622. doi:10.1080/09638288.2016.1206631

76. Marzolini S, Oh P, McIlroy W, Brooks D. The effects of an aerobic and resistance exercise training program on cognition following stroke. Neurorehabil Neural Repair. 2013;27(5):392-402. doi: $10.1177 / 1545968312465192$ 
77. Allida S, Cox KL, Hsieh C-F, Lang H, House A, Hackett ML. Pharmacological, psychological, and non-invasive brain stimulation interventions for treating depression after stroke. Cochrane Database Syst Rev. 2020;1(1):CD003437.

78. Wiltrout C, Lang B, Yan Y, Dempsey RJ, Vemuganti R. Repairing brain after stroke: a review on post-ischemic neurogenesis. Neurochem Int. 2007;50(7-8):1028-1041. doi:10.1016/j. neuint.2007.04.011

79. Siepmann T, Penzlin AI, Kepplinger J, et al. Selective serotonin reuptake inhibitors to improve outcome in acute ischemic stroke: possible mechanisms and clinical evidence. Brain Behav. 2015;5 (10):1-7. doi:10.1002/brb3.373

80. Tae KS, Mi SK, Ho YL, et al. Fluoxetine and sertraline attenuate postischemic brain injury in mice. Korean $J$ Physiol Pharmacol. 2009;13(3):257-263. doi:10.4196/kjpp.2009.13.3.257
81. Mead GE, Dennis M, Lundström E, Murray V, Hackett M, Hankey GJ. Letter by mead et al regarding article, "selective serotonin reuptake inhibitors for stroke: more trials are needed". Stroke. 2013;44(4):e40-1. doi:10.1161/STROKEAHA.112.681130

82. Lim CM, Kim SW, Park JY, Kim C, Yoon SH, Lee JK. Fluoxetine affords robust neuroprotection in the postischemic brain via its anti-inflammatory effect. J Neurosci Res. 2009;87(4):1037-1045. doi:10.1002/jnr.21899

83. Gu WG, Brännström T, Wester P. Cortical neurogenesis in adult rats after reversible photothrombotic stroke. J Cereb Blood Flow Metab. 2000;20(8):1166-1173. doi:10.1097/00004647-200008000-00002

\section{Publish your work in this journal}

Neuropsychiatric Disease and Treatment is an international, peerreviewed journal of clinical therapeutics and pharmacology focusing on concise rapid reporting of clinical or pre-clinical studies on a range of neuropsychiatric and neurological disorders. This journal is indexed on PubMed Central, the 'PsycINFO' database and CAS, and is the official journal of The International Neuropsychiatric Association (INA). The manuscript management system is completely online and includes a very quick and fair peer-review system, which is all easy to use. Visit http://www.dovepress.com/testimonials.php to read real quotes from published authors. 